\title{
Comparison of Laminar and Turbulent Thermal Plasma Jet Characteristics - A Modeling Study
}

\author{
Kai Cheng · Xi Chen · Wenxia Pan
}

Received: 16 June 2005; Accepted: 17 October 2005 /

Published online: 21 April 2006

(C) Springer Science+Business Media, Inc. 2006

\begin{abstract}
Modeling results are presented to compare the characteristics of laminar and turbulent argon thermal plasma jets issuing into ambient air. The combined-diffusion-coefficient method and the turbulence-enhanced combined-diffusion-coefficient method are employed to treat the diffusion of ambient air into the laminar and turbulent argon plasma jects, respectively. It is shown that since only the molecular diffusion mechanism is involved in the laminar plasma jet, the mass flow rate of ambient air entrained into the laminar plasma jet is comparatively small and less dependent on the jet inlet velocity. On the other hand, since turbulent transport mechanism is dominant in the turbulent plasma jet, the entrainment rate of ambient air into the turbulent plasma jet is about one order of magnitude larger and almost directly proportional to the jet inlet velocity. As a result, the characteristics of laminar plasma jets are quite different from those of turbulent plasma jets. The length of the high-temperature region of the laminar plasma jet is much longer and increases notably with increasing jet inlet velocity or inlet temperature, while the length of the high-temperature region of the turbulent plasma jet is short and less influenced by the jet inlet velocity or inlet temperature. The predicted results are reasonably consistent with available experimental observation by using a DC arc plasma torch at arc currents $80-250 \mathrm{~A}$ and argon flow rates $(1.8-7.0) \times 10^{-4} \mathrm{~kg} / \mathrm{s}$.
\end{abstract}

Keywords Thermal plasma $\cdot$ laminar and turbulent jets $\cdot$ comparative study $\cdot$ modeling

\section{Introduction}

DC arc thermal plasmas have been used in industry and in labs [1,2] for many years, such as plasma spraying, plasma cutting and welding, thermal plasma waste destruction, thermal plasma synthesis of fine powders, and so on. Plasma jets encountered in those applications are usually in the turbulent flow state, especially for the cases where comparatively large

K. Cheng · Xi Chen $(\varangle)$

Department of Engineering Mechanics, Tsinghua University, Beijing 100084, China

e-mail: cx-dem@mail.tsinghua.edu.cn 
surface area or materials volume is processed and/or comparatively high production rate and thus comparatively high power level are required. Numerous experimental and modeling studies have been performed in past decades concerning the turbulent plasma jet characteristics (e.g. see [1-14] and the references cited therein). The turbulent plasma jets are usually accompanied by large parameter fluctuations (mainly caused by the arc-root fluctuation at torch anode), intense noise emission (noise intensity level may be as high as $120 \mathrm{~dB}$ ), strong entrainment of ambient gas into the plasma jets and thus with short high-temperature region lengths and steep axial gradients of plasma parameters (e.g. the temperature gradient may be as high as $5 \times 10^{5} \mathrm{~K} / \mathrm{m}$, whereas axial velocity gradient as large as $\left.5 \times 10^{4}(\mathrm{~m} / \mathrm{s}) / \mathrm{m}\right)$. These special features of the turbulent plasma jets are often not favorable from the viewpoint of materials processing, because they will worsen the working surroundings of operators, reduce the process repeatability and controllability, and increase the oxidization degree of metallic materials processed in air surroundings.

Long laminar thermal plasma jets have been successfully generated at atmospheric pressure recently using elaborated designed DC non-transferred arc plasma torches [15-18]. For the plasma torch with an anode-nozzle of 4 or $8 \mathrm{~mm}$ inner diameter, the visual length of the generated long laminar plasma jet can be as long as $550 \mathrm{~mm}$ or more. In comparison with the turbulent plasma jet, the marked advantages of the long laminar plasma jet are that it is quite stable; its noise-emission intensity is negligibly low; the entrainment of ambient gas into the plasma jet is significantly reduced and thus the high-temperature region length of laminar plasma jet is much longer and the axial gradients of plasma parameters (temperature, velocity and species concentration) within the jet are much smaller. These merits of the long laminar plasma jet make it very attractive from the viewpoint of materials processing, since it provides the possibility of achieving low noise-level working surroundings, better process controllability and repeatability, and reduced oxidization degree of metallic materials exposed to the plasma jet, even if the materials are processed in air surroundings. It is anticipated that the long laminar plasma jet will find its position in materials processing, at least for the cases where not too large surface area or materials volume is to be processed and/or not too high jet-power level is required. Indeed, preliminary attempts [17, 19, 20] using long laminar plasma jets in the preparation of thermal barrier coatings, in the re-melting hardening of cast iron surfaces and in the stainless-steel surface cladding have shown promising results.

With the same DC non-transferred arc plasma torch, both laminar and turbulent thermal plasma jets can be generated in experiments $[17,18,21]$ and thus it is possible to compare the characteristics of laminar and turbulent thermal plasma jets for a given plasma torch. Experimental observations $[17,18,21]$ show that silent long laminar plasma jets and noisy short turbulent plasma jets are generated at lower and higher flow rates, respectively. Between the laminar and turbulent flow regimes there exists an unsteady transitional flow regime. For the laminar plasma jet, the high-temperature region length of the jet (which will be called jet length hereafter) increases with increasing working-gas flow rate or arc current and thus the jet length can be easily adjusted by changing the working-gas flow rate or the arc current of the plasma torch. On the other hand, the jet length for the turbulent plasma jet is much shorter and less depends on the working-gas flow rate or arc current of the plasma torch.

For the DC non-transferred arc plasma torch with a specially designed inter-electrode insert for facilitating the generation of the laminar plasma jet, reference 18 presented a series of photographs to show how the laminar plasma jet length increases with increasing arc current (in the range of 75-200 A) of the plasma torch for the laminar argon plasma jet issuing into ambient air with a fixed argon flow rate $\left(1.9 \times 10^{-4} \mathrm{~kg} / \mathrm{s}\right)$. Additional photographs are presented here in Fig. 1 to show how the plasma jet length varies with the argon flow rate in the range of $(1.7-3.7) \times 10^{-4} \mathrm{~kg} / \mathrm{s}$ for a given arc current $(200 \mathrm{~A})$. It is seen from Fig. 1 


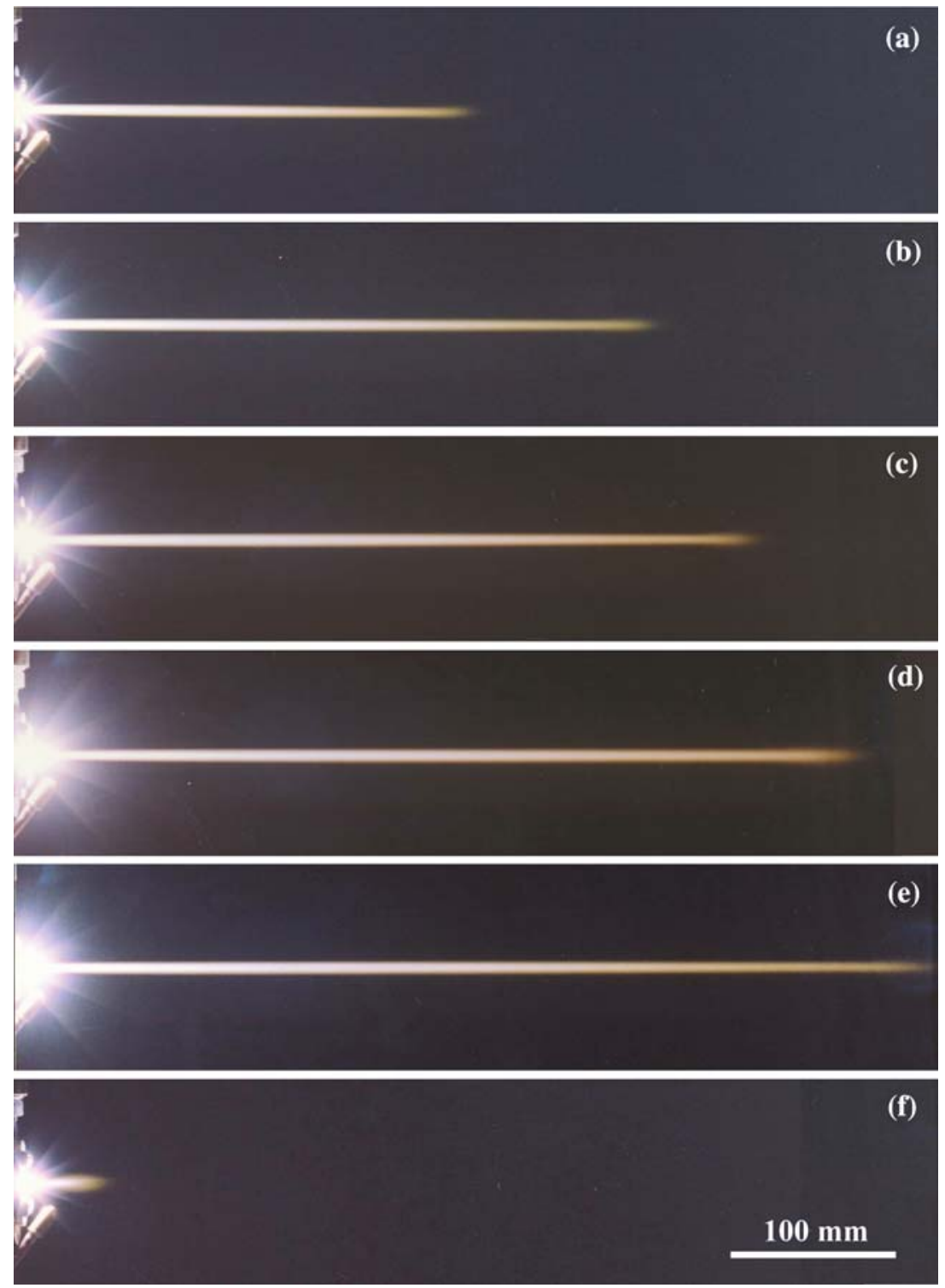

Fig. 1 Variation of the visual plasma jet length with the argon flow rate. (a)-(f) correspond to the argon mass flow rates of $1.7,2.1,2.4,2.7,2.9$ and $3.7 \times 10^{-4} \mathrm{~kg} / \mathrm{s}$. Arc current $200 \mathrm{~A}$

that in the laminar flow regime with comparatively low working-gas flow rates, the plasma jet length notably increases with increasing flow rate, while the plasma jet length becomes very short at the high gas flow rate where turbulent flow regime is involved. These results are qualitatively consistent with those obtained in recent experiments [21] by using somewhat different torch structures.

Although many papers have been published concerning the turbulent thermal plasma jet characteristics [1-14] and a number of papers have been published concerning the laminar 
thermal plasma jet characteristics $[6,8,15-26]$, so far there is no a systematic study that compares carefully the laminar and turbulent thermal plasma jet characteristics. References 6 and 8 compared the predicted characteristics of laminar and turbulent plasma jets, but the comparisons were not sufficient and the conclusion deduced from reference 8 was not consistent with that from reference 6 . For example, reference 6 presented two figures of computed isotherms, respectively, for the laminar and turbulent argon plasma jets issuing into ambient air and showed that the rate of axial decrease of plasma temperature in the laminar plasma jet is much slower than that in the turbulent one, in qualitative agreement with the experimental observation mentioned above. However, the modeling results of reference 8 showed that the decrease rate of plasma temperature along the axis of the laminar argon plasma jet is only slightly slower than that of the turbulent argon plasma jet issuing into argon surroundings. In this paper, modeling results are presented for the argon plasma jets issuing into ambient air with different jet inlet temperatures and inlet velocities to compare the laminar and turbulent plasma jet characteristics and to reveal why such large differences exist between the laminar and turbulent plasma jet characteristics. The combined-diffusion-coefficient method proposed by Murphy [27-29] is employed to treat the diffusion of ambient air into the laminar argon plasma jet, while the turbulence-enhanced combined-diffusion-coefficient method [14] is used to deal with the diffusion of ambient air into the turbulent argon plasma jet based on the following consideration. Since many different gas species ( $\mathrm{Ar}, \mathrm{Ar}^{+}, e, \mathrm{~N}_{2}, \mathrm{~N}$, $\mathrm{N}^{+}, \mathrm{N}_{2}^{+}, \mathrm{O}_{2}, \mathrm{O}, \mathrm{O}^{+}$, etc.) occur in the plasma jets, the strict treatment of species diffusion is quite complicated even for the laminar plasma jet and for the LTE (local thermodynamic equilibrium) and LCE (local chemical equilibrium) case. In order to simplify the species diffusion treatment, Murphy proposed a combined-diffusion-coefficient method [27-29] in which only the diffusion between two different gases needs to be handled. This approach can significantly simplify the species diffusion study. According to Murphy's opinion [29], his combined-diffusion-coefficient method is equivalent to the full multi-component diffusion treatment provided that the gases do not react with each other and are homo-nuclear. It is expected that this approach is also a good approximation for the argon-air mixture at the LCE state, although air is not a homo-nuclear gas. Hence, the combined-diffusion-coefficient method is used in this study to treat the diffusion of ambient air into the laminar plasma jet. On the other hand, for the turbulent plasma jet, turbulent diffusion will be the dominant mechanism. Reference 13 performed a modeling study of the turbulent argon plasma jet issuing into ambient air using the computer code LAVA. Continuity, momentum, energy and species conservation equations and the ordinary $K-\varepsilon$ two-equation turbulence model were employed. Neutrals, ions and electrons were considered as separate components of the gas mixture, and general kinetic and equilibrium chemistry algorithms were used to compute ionization, dissociation, recombination and other chemical reactions for the species diffusion study [13]. Although the $K-\varepsilon$ two-equation turbulence model could not reveal some special features of the turbulent plasma jet, such as the engulfment entrainment and non-equilibrium transport [5], the modeling results concerning the jet temperature, velocity and species concentration fields were shown to be reasonably consistent with corresponding experimental data $[12,13]$. Reference 14 studied the same problem with almost the same approach as in Reference 13 except that a turbulence-enhanced combined-diffusion-coefficient method was employed to deal with the diffusion of ambient air into the turbulent argon plasma jet. Using the turbulence-enhanced combined-diffusion-coefficient method could significantly reduce the numerical effort. Nevertheless, it was found [14] that the agreement between the predicted jet temperature, velocity and species concentration profiles with corresponding experimental data was as good as that obtained in reference 13. It seems that this situation is due to the fact that turbulent transport mechanism is dominant for the turbulent plasma jet, whereas the 
$K-\varepsilon$ two-equation turbulence model is employed in both references 13 and 14 to treat the turbulence. Hence, the turbulence-enhanced combined-diffusion-coefficient method is also used in this study to handle the diffusion of ambient air into the turbulent argon plasma jet.

\section{Modeling approach}

Main assumptions employed to study the characteristics of laminar argon plasma jets issuing into ambient air include (i) the jet flow is steady and axi-symmetrical; (ii) the plasma is in the LTE and LCE state and optically thin to radiation; (iii) the swirling velocity component can be neglected in comparison with the axial velocity; (iv) the diffusion of argon within the argon-air mixture can be handled by use of the combined-diffusion-coefficient method [27-29]; and (v) the buoyancy effects can be ignored due to their smallness [23, 24].

The continuity, momentum and energy equations can thus be written as follows:

$$
\begin{aligned}
\frac{\partial}{\partial x}(\rho u)+\frac{1}{r} \frac{\partial}{\partial r}(r \rho v)= & 0 \\
\frac{\partial(\rho u u)}{\partial x}+\frac{1}{r} \frac{\partial(r \rho u v)}{\partial r}= & -\frac{\partial p}{\partial x}+2 \frac{\partial}{\partial x}\left(\mu \frac{\partial u}{\partial x}\right)+\frac{1}{r} \frac{\partial}{\partial r}\left[r \mu\left(\frac{\partial u}{\partial r}+\frac{\partial v}{\partial x}\right)\right] \\
\frac{\partial(\rho u v)}{\partial x}+\frac{1}{r} \frac{\partial(r \rho v v)}{\partial r}= & -\frac{\partial p}{\partial r}+\frac{2}{r} \frac{\partial}{\partial r}\left(r \mu \frac{\partial v}{\partial r}\right)+\frac{\partial}{\partial x}\left[\mu\left(\frac{\partial v}{\partial x}+\frac{\partial u}{\partial r}\right)\right]-2 \mu \frac{v}{r^{2}} \\
\frac{\partial(\rho u h)}{\partial x}+\frac{1}{r} \frac{\partial(r \rho v h)}{\partial r}= & \frac{\partial}{\partial x}\left[\frac{k}{c_{\mathrm{p}}} \frac{\partial h}{\partial x}\right]+\frac{1}{r} \frac{\partial}{\partial r}\left[r \frac{k}{c_{\mathrm{p}}} \frac{\partial h}{\partial r}\right]-U_{\mathrm{r}}-\frac{\partial}{\partial x}\left[\left(h_{\mathrm{A}}-h_{\mathrm{B}}\right) J_{\mathrm{x}}\right] \\
& -\frac{1}{r} \frac{\partial}{\partial r}\left[r\left(h_{\mathrm{A}}-h_{\mathrm{B}}\right) J_{\mathrm{r}}\right]-\frac{\partial}{\partial x}\left[\frac{k}{c_{\mathrm{p}}}\left(h_{\mathrm{A}}-h_{\mathrm{B}}\right) \frac{\partial f_{\mathrm{A}}}{\partial x}\right] \\
& -\frac{1}{r} \frac{\partial}{\partial r}\left[r \frac{k}{c_{\mathrm{p}}}\left(h_{\mathrm{A}}-h_{\mathrm{B}}\right) \frac{\partial f_{\mathrm{A}}}{\partial r}\right]
\end{aligned}
$$

Here $u$ and $v$ are the axial $(x-)$ and radial $(r-)$ velocity components; $p$ the pressure; and $\rho, \mu, k, c_{\mathrm{p}}, h$ and $U_{\mathrm{r}}$ are the temperature- and composition-dependent plasma density, viscosity, thermal conductivity, specific heat at constant pressure, specific enthalpy and radiation power per unit volume of plasma, respectively. In Eq. (4), all the terms containing $\left(h_{\mathrm{A}}-h_{\mathrm{B}}\right)$ represent the contribution of species diffusion to the energy transport [22], where $h_{\mathrm{A}}$ and $h_{\mathrm{B}}$ are the temperature-dependent specific enthalpies of gases A (pure argon) and B (pure air), respectively. $f_{\mathrm{A}}$ is the mass fraction of argon in the argon-air mixture and is solved by use of the following species conservation equation:

$$
\frac{\partial\left(\rho u f_{\mathrm{A}}\right)}{\partial x}+\frac{1}{r} \frac{\partial\left(r \rho v f_{\mathrm{A}}\right)}{\partial r}=\frac{\partial}{\partial x}\left[\Gamma_{f} \frac{\partial f_{\mathrm{A}}}{\partial x}\right]+\frac{1}{r} \frac{\partial}{\partial r}\left[r \Gamma_{f} \frac{\partial f_{\mathrm{A}}}{\partial r}\right]+S_{f}
$$

$J_{\mathrm{X}}$ and $J_{\mathrm{r}}$ are the axial $(x-)$ and radial $(r-)$ components of the following argon diffusion mass flux vector [27]

$$
\vec{J}_{\mathrm{A}}=-\left(n^{2} / \rho\right) \bar{m}_{\mathrm{A}} \bar{m}_{\mathrm{B}} \bar{D}_{\mathrm{AB}}^{x} \nabla X_{\mathrm{A}}-\bar{D}_{\mathrm{AB}}^{T} \nabla \ln T
$$

in which $n$ is the total gas-particle number density, $\bar{m}_{\mathrm{A}}$ and $\bar{m}_{\mathrm{B}}$ are the averaged gas-particle masses for all the heavy particles (excluding electrons) coming from argon (i.e. species A) and those from air (i.e. species B), $X_{\mathrm{A}}$ is the mole fraction of argon in the argon-air mixture, whereas $\bar{D}_{\mathrm{AB}}^{x}$ and $\bar{D}_{\mathrm{AB}}^{T}$ are the combined ordinary diffusion coefficient associated with the argon mole-fraction gradient $\nabla X_{\mathrm{A}}$ and the combined thermal diffusion coefficient associated 
with the temperature gradient $\nabla T$, respectively [27]. The transport coefficient in Eq. (5) can be expressed as [22] $\Gamma_{f}=\left[\bar{m}_{\mathrm{A}} \bar{m}_{\mathrm{B}} /\left(\bar{M} \bar{M}_{\mathrm{A}}\right)\right] \rho \bar{D}_{\mathrm{AB}}^{x}$, in which $\bar{M}$ and $\bar{M}_{\mathrm{A}}$ are the averaged gas-particle mass for all the gas particles (including electrons) of the gas mixture and that for all the gas particles coming from argon [27], respectively. The source term $S_{f}$ in Eq. (5) can be expressed as [22, 23]

$$
\begin{aligned}
S_{f}= & \frac{1}{r} \frac{\partial}{\partial r}\left(r \Gamma_{f} \frac{f_{\mathrm{A}}}{\bar{M}} \frac{\partial \bar{M}}{\partial r}\right)-\frac{1}{r} \frac{\partial}{\partial r}\left(r \Gamma_{f} \frac{f_{\mathrm{A}}}{\bar{M}_{\mathrm{A}}} \frac{\partial \bar{M}_{\mathrm{A}}}{\partial r}\right)+\frac{\partial}{\partial x}\left(\Gamma_{f} \frac{f_{\mathrm{A}}}{\bar{M}} \frac{\partial \bar{M}}{\partial x}\right) \\
& -\frac{\partial}{\partial x}\left(\Gamma_{f} \frac{f_{\mathrm{A}}}{\bar{M}_{\mathrm{A}}} \frac{\partial \bar{M}_{\mathrm{A}}}{\partial x}\right)+\frac{1}{r} \frac{\partial}{\partial r}\left(r \bar{D}_{\mathrm{AB}}^{T} \frac{\partial \ln T}{\partial r}\right)+\frac{\partial}{\partial x}\left(\bar{D}_{\mathrm{AB}}^{T} \frac{\partial \ln T}{\partial x}\right)
\end{aligned}
$$

On the other hand, for the study of the characteristics of turbulent argon plasma jets issuing into ambient air, all the physical quantities appearing in foregoing equations will be their time-averaged values. The molecular transport coefficients appearing in the conservation Eqs. (2) - (5) are substituted by their counterparts containing both the turbulent and molecular contributions. Namely, $\mu$ in Eqs. (2) and (3) should be substituted by $\left(\mu_{\mathrm{t}}+\mu\right), k / c_{\mathrm{p}}$ in Eq. (4) substituted by $\left[\left(\mu_{\mathrm{t}} / P r_{h}\right)+\left(k / c_{\mathrm{p}}\right)\right]$, and $\Gamma_{f}$ in Eq. (5) substituted by $\left[\left(\mu_{\mathrm{t}} / S c_{f}\right)+\Gamma_{f}\right]$. In addition, an additional term representing the turbulent diffusion flux, i.e. $-\left(\mu_{\mathrm{t}} / S c_{f}\right) \nabla f_{\mathrm{A}}$, should be added into the right-hand side of Eq. (6) for the argon diffusion mass flux vector $\vec{J}_{\mathrm{A}}$. Here $\mu_{\mathrm{t}}$ is the turbulent viscosity, and $\mu_{\mathrm{t}}$ is calculated by $\mu_{\mathrm{t}}=C_{\mu} \rho K^{2} / \varepsilon$ when the $K-\varepsilon$ two-equation turbulence model is employed [13, 14]. Here $K$ and $\varepsilon$ are the turbulent kinetic energy and its dissipation rate, and are computed by the following equations:

$$
\begin{aligned}
\frac{\partial(\rho u K)}{\partial x}+\frac{1}{r} \frac{\partial(r v \rho K)}{\partial r}= & \frac{\partial}{\partial x}\left[\left(\mu+\frac{\mu_{\mathrm{t}}}{P r_{K}}\right) \frac{\partial K}{\partial x}\right] \\
& +\frac{1}{r} \frac{\partial}{\partial r}\left[r\left(\mu+\frac{\mu_{\mathrm{t}}}{P r_{K}}\right) \frac{\partial K}{\partial r}\right]+G-\rho \varepsilon \\
\frac{\partial(\rho u \varepsilon)}{\partial x}+\frac{1}{r} \frac{\partial(r v \rho \varepsilon)}{\partial r}= & \frac{\partial}{\partial x}\left[\left(\mu+\frac{\mu_{\mathrm{t}}}{P r_{\varepsilon}}\right) \frac{\partial \varepsilon}{\partial x}\right] \\
& +\frac{1}{r} \frac{\partial}{\partial r}\left[r\left(\mu+\frac{\mu_{\mathrm{t}}}{P r_{\varepsilon}}\right) \frac{\partial \varepsilon}{\partial r}\right]+\frac{\varepsilon}{K}\left(C_{1} G-C_{2} \rho \varepsilon\right)
\end{aligned}
$$

$C_{\mu}, C_{1}, C_{2}, P r_{h}, \mathrm{Sc}_{f}, \operatorname{Pr}_{K}$ and $P r_{\varepsilon}$ are constants in the turbulence model, and in this study they are assigned their commonly adopted values, i.e. $0.09,1.44,1.92,0.9,1.0,1.0$ and 1.3, respectively. The turbulence generation term, $G$, in Eqs. (8) and (9) is expressed as

$$
G=\mu_{\mathrm{t}}\left[2\left(\frac{\partial v}{\partial r}\right)^{2}+2\left(\frac{\partial u}{\partial x}\right)^{2}+2\left(\frac{v}{r}\right)^{2}+\left(\frac{\partial u}{\partial r}+\frac{\partial v}{\partial x}\right)^{2}\right]
$$

The computational domain used in the modeling is denoted as A-B-C-D-E-F-A in Fig. 2. The radius of the jet inlet $(\mathrm{AB})$ is $4 \mathrm{~mm}$. The radial size (AD) of the computational domain is taken to be $50 \mathrm{~mm}$, whereas the axial size (DE or AF) is $100 \mathrm{~mm}$ for the turbulent jets and $400 \mathrm{~mm}$ for the laminar jets, respectively. The number of grid points employed in the computation is 124 ( $x$-direction) $\times 78$ ( $r$-direction). Non-uniform mesh is adopted with finer mesh spacing near the jet axis and the jet inlet.

Boundary conditions are as follows.

(i) At the jet inlet $(\mathrm{A}-\mathrm{B}): v=0, f_{\mathrm{A}}=1.0$, and the following profiles of axial velocity and temperature are used:

$$
u=U_{0}\left[1-\left(r / R_{\text {in }}\right)^{1.4}\right], \quad T=\left(T_{0}-T_{\mathrm{W}}\right)\left[1-\left(r / R_{\text {in }}\right)^{2.3}\right]+T_{\mathrm{W}}
$$




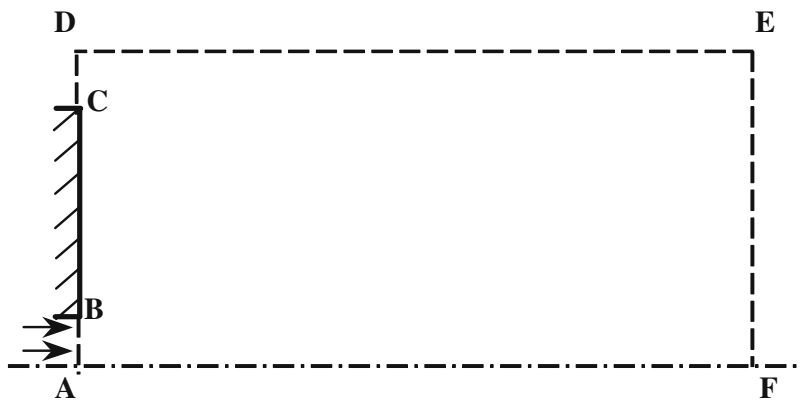

Fig. 2 Computational domain used in the modeling study

in which $R_{\text {in }}$ is the radius of the jet inlet section ( $4 \mathrm{~mm}$ ), $U_{0}$ and $T_{0}$ are the maximum axial velocity and temperature at jet axis, respectively, whereas $T_{\mathrm{w}}$ is the inner wall temperature of plasma torch and $T_{w}=700 \mathrm{~K}$. The axial-velocity and temperature profiles (11) were employed in a few previous studies [13,14] and were shown to be able to predict plasma temperature, velocity and species concentration fields in reasonable agreement with corresponding experimental data for a typical turbulent argon plasma jet issuing into ambient air $[13,14]$. For facilitating the comparison of laminar and turbulent plasma jet characteristics, the same jet-inlet velocity and temperature profiles are used in this study for both the laminar and turbulent plasma jets. For the turbulent cases, $K=0.00005 \times u_{\text {in }}^{2}$ and $\varepsilon=K^{\frac{3}{2}} / L$ are used at the jet inlet section A-B, where $L=0.075 \delta_{0.1} / C_{\mu}^{3 / 4}$, and $\delta_{0.1}$ is the jet width defined by the radial distance at which the axial velocity reduces to $u=0.1 U_{0}[13,14]$.

(ii) At the rear surface B-C of the plasma torch wall, for the laminar case, $u=v=0$ and zero diffusion flux are employed, and the wall temperature is assumed to vary in the radial direction according to the relation $T(\mathrm{~K})=700-400 \frac{\ln \left(r / R_{\text {in }}\right)}{\ln \left(R_{\text {out }} / R_{\text {in }}\right)}$, in which $R_{\text {in }}$ and $R_{\text {out }}$ are the inner-wall radius and outer-wall radius of the plasma torch. For the turbulent jet case, the wall function method is used to treat the $\mathrm{B}-\mathrm{C}$ boundary conditions.

(iii) At the left free boundary $\mathrm{C}-\mathrm{D}$, the following conditions are used:

$$
\partial u / \partial x=0, \quad \partial v / \partial x=0, \quad T=300 \mathrm{~K}, \quad f_{A}=0, \quad K=0, \quad \varepsilon=0
$$

(iv) Along the top free boundary D-E, the following conditions are employed:

$$
\partial u / \partial r=0, \quad \partial(\rho r v) / \partial r=0, \quad T=300 \mathrm{~K}, \quad f_{A}=0, \quad K=0, \quad \varepsilon=0
$$

(v) At the downstream boundary E-F, the following one-way conditions are used:

$$
\partial \phi / \partial x=0 \quad\left(\phi=u, v, h, f_{A}, K, \varepsilon\right)
$$

(vi) Along the jet axis A-F, the axi-symmetrical conditions are employed:

$$
\partial \phi / \partial r=0\left(\phi=u, h, f_{A}, K, \varepsilon\right), \quad v=0
$$

The SIMPLER algorithm [30] is used to solve the governing Eqs. (1)-(5), (8) and (9) associated with corresponding boundary conditions to obtain the velocity, specific enthalpy, concentration and turbulent parameter (for turbulent jet) fields in the plasma jets. The temperature field can be easily calculated from the computed distributions of the specific enthalpy and argon mass fraction using the argon-air plasma property tables compiled for different temperatures and different argon mass fractions. 


\section{Results and discussion}

Typical modeling results are presented in Figs. 3-16 to compare the characteristics of laminar and turbulent argon plasma jets issuing into the air surroundings at atmospheric pressure. In order to reveal more clearly the difference between laminar and turbulent plasma jet characteristics, the same radial profiles of plasma axial-velocity and temperature at the jetinlet, as given in Eq. (11), and the same maximum axial-velocity $U_{0}$ or maximum temperature $T_{0}$ at the jet-inlet center are used ( $U_{0}$ will be called the jet-inlet velocity and $T_{0}$ the jet-inlet temperature hereafter). It is noted that in experiments sometimes both laminar and turbulent plasma jets may be generated under almost the same jet inlet conditions [18, 21]. For example, when the jet flow is within the unsteady transitional flow state, a silent long laminar plasma jet and a noisy short turbulent plasma jet may occur alternately. When a turbulent disturbance is artificially created at the inlet of a laminar jet, the laminar plasma jet may transform into the turbulent plasma jet.

Figure 3 compares typical computed streamlines of laminar and turbulent plasma jets. The estimated Reynolds number using the jet-inlet argon mass flow-rate and inlet diameter as well as the integrally averaged viscosity is 1036 . As a consequence of the continuous entrainment of ambient air into the plasma jets, both the laminar and turbulent jet widths increase with increasing axial distance from the jet inlet. It should be noted that the streamline interval for the laminar case in Fig. 3(a) is one fifth of that for the turbulent case in Fig. 3(b), and thus the mass flow rate of the ambient air entrained into the laminar plasma jet is about one order of magnitude less than that into the turbulent plasma jet up to the axial section $100 \mathrm{~mm}$ from the jet inlet. As a result, the spreading angle of the jet edge for the laminar plasma jet $\left(\sim 0.5^{\circ}\right)$ is much less than that for the turbulent plasma jet $\left(\sim 12^{\circ}\right)$. Much smaller spreading angle was also shown in the computed results of reference 6 for the laminar plasma jet than the turbulent plasma jet.

Figures 4-6 compare the computed isotherms, axial-velocity contours and argon mass fraction contours, respectively, for the laminar (a) and turbulent (b) plasma jets with the same jet-inlet conditions. Since the flow rate of the ambient air entrained into the laminar plasma jet is much less than that into the turbulent plasma jet, the axial gradients of plasma parameters (temperature, axial velocity and argon concentration) in the laminar plasma jet are appreciably smaller than their counterparts in the turbulent plasma jet.

Comparison of Fig. 4(a) with (b) shows that, as observed in the experiments [17, 18, 21], the predicted length of the high-temperature region of the laminar plasma jet is much longer than that of the turbulent plasma jet. For example, if we use the maximum axial distance from the jet inlet of the isotherm of $3000 \mathrm{~K}$ as the jet length, the laminar plasma jet length appreciably exceeds $400 \mathrm{~mm}$ (as long as about $600 \mathrm{~mm}$ ) while the turbulent plasma jet length is less than $45 \mathrm{~mm}$ for this case. The laminar plasma jet thus assumes much smaller axial gradients of plasma temperature than the turbulent one. This feature of the laminar plasma jet is advantageous for the heating of particulate matter injected into the jet. On the other hand, since the high-temperature region length of the laminar plasma jet is comparatively long while the mixing layer between the laminar plasma jet and the ambient air is comparatively thin (jet spreading angle is comparatively small), the radial gradients of plasma temperature in the laminar plasma jet are larger than those in the turbulent one. This feature of the laminar plasma jet seems disadvantageous for the lateral feeding of particulate matter into the jet high-temperature region. However, both experimental [26] and modeling [22] results demonstrated that the particulate matter could still be laterally injected into the laminar plasma jet by careful adjusting the carrier-gas parameters.

Similar features are also observed in Figs. 5 and 6. Figure 5(a) and (b) show that the axial velocity at the axis of the laminar plasma jet is higher than $400 \mathrm{~m} / \mathrm{s}$ even at the axial location 

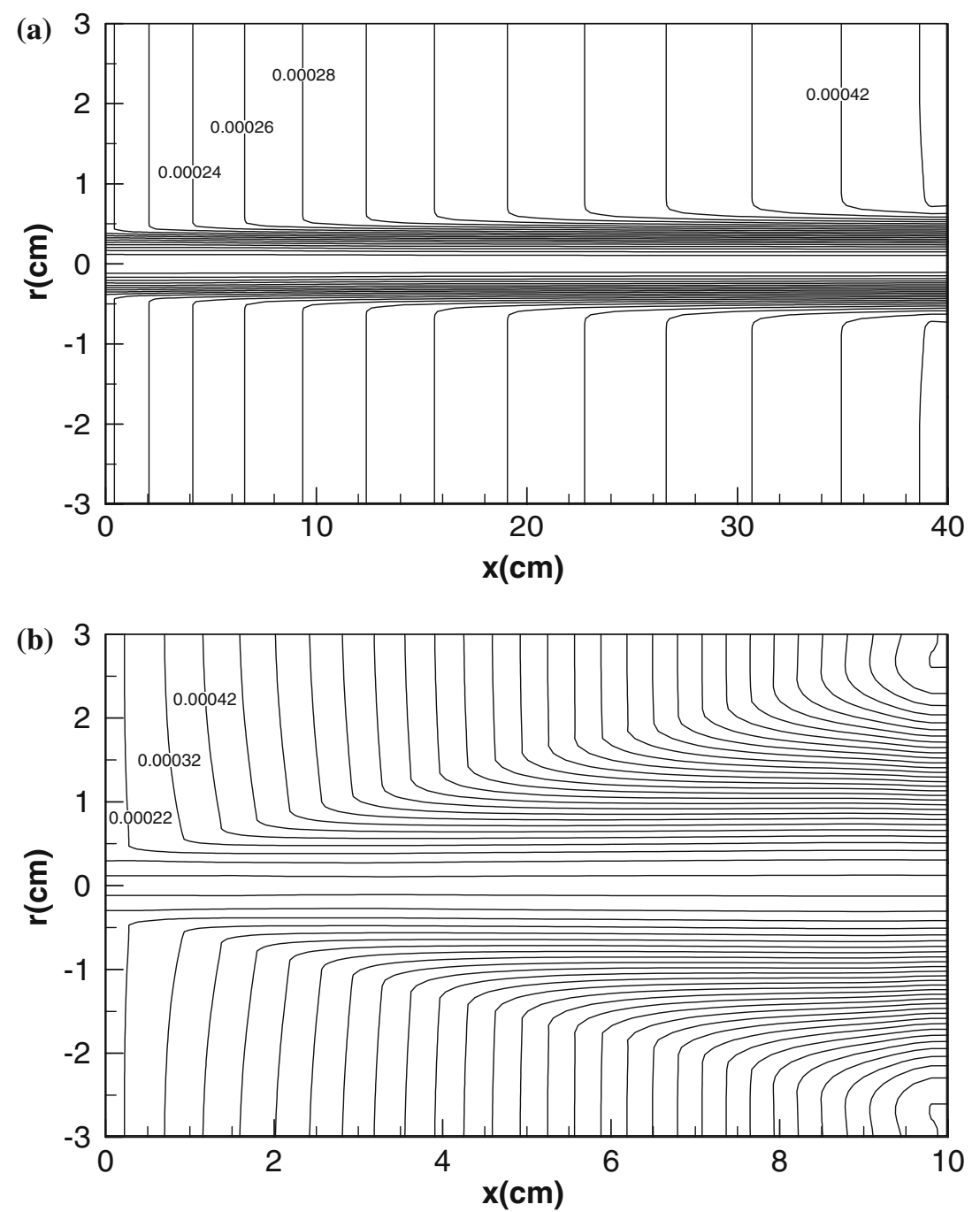

Fig. 3 Comparison of the computed streamlines in plasma jets $\left(U_{0}=1000 \mathrm{~m} / \mathrm{s}, T_{0}=13,000 \mathrm{~K}\right)$. (a) Laminar plasma jet, interval: $2 \times 10^{-5} \mathrm{~kg} / \mathrm{s}$ per radian; (b) turbulent plasma jet, interval: $10^{-4} \mathrm{~kg} / \mathrm{s}$ per radian

$400 \mathrm{~mm}$ from the jet inlet, while it has dropped to $300 \mathrm{~m} / \mathrm{s}$ at $40 \mathrm{~mm}$ location in the turbulent plasma jet. Figure 6 shows that the argon mass fraction $f_{\mathrm{A}}$ on the laminar jet axis is larger than 0.7 even at the axial location $400 \mathrm{~mm}$, while $f_{\mathrm{A}}$ has decreased to 0.5 for the turbulent plasma jet at the axial location $30 \mathrm{~mm}$ from the jet inlet.

Since the laminar plasma jet lengths are much longer than the turbulent plasma jet ones, the axial size of the computational domain used for the modeling of the laminar plasma jets has been taken to be $400 \mathrm{~mm}$ instead of $100 \mathrm{~mm}$ for the turbulent plasma jets. However, the same axial length $(100 \mathrm{~mm})$ will be used in the following to present the computed results of both the laminar and turbulent plasma jets for easier comparison. For the cases with a fixed jet-inlet temperature $\left(T_{0}=13000 \mathrm{~K}\right)$ but different jet-inlet velocities $\left(U_{0}=200,400\right.$, 600,800 and $1000 \mathrm{~m} / \mathrm{s}$ for laminar jets, whereas $U_{0}=800,1000,1200,1400$ and $1600 \mathrm{~m} / \mathrm{s}$ 

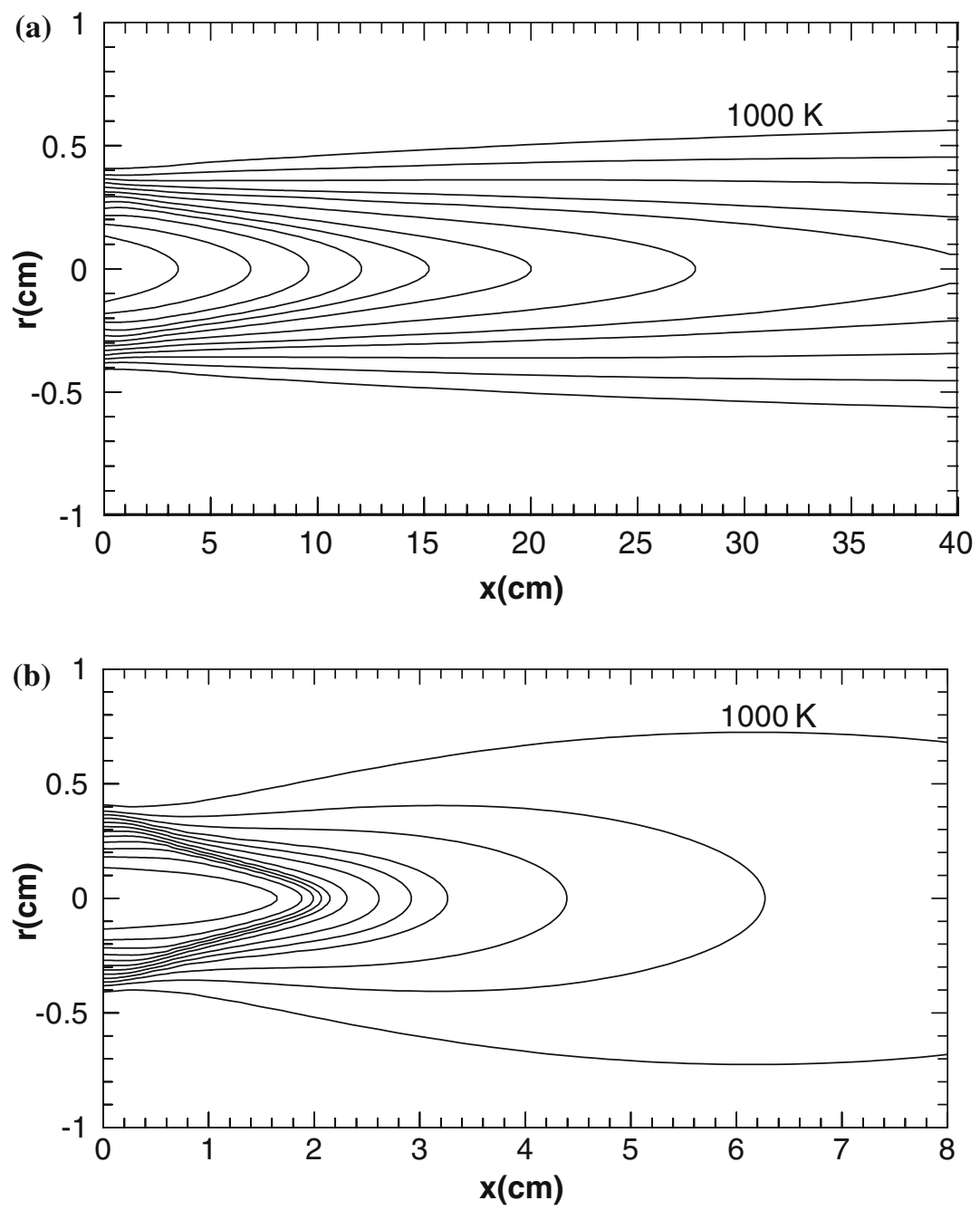

Fig. 4 Comparison of the isothermal lines in typical laminar (a) and turbulent (b) plasma jets $\left(U_{0}=1000 \mathrm{~m} / \mathrm{s}\right.$, $\left.T_{0}=13,000 \mathrm{~K}\right)$. Outer line $-1000 \mathrm{~K}$; interval $-1000 \mathrm{~K}$

for turbulent jets), Figs. 7-9 compare the axial variations of the plasma temperature, axial velocity and argon mass fraction, respectively, along the jet axis for the laminar and turbulent plasma jets. As a sequence of the continuous entrainment of ambient air into the plasma jets, those plasma parameters (plasma temperature, axial velocity, argon mass fraction) always decrease with increasing axial distance from the jet inlet. Since the air entrainment rates for the laminar plasma jets are much less than their counterparts for the turbulent plasma jets, Figs. 7-9 show that the rates of axial decrease of the plasma parameters for the laminar plasma jets are appreciably less than those for the turbulent plasma jets. For example, at the axial location $30 \mathrm{~mm}$ from the jet inlet and for the case with jet-inlet velocity of $1000 \mathrm{~m} / \mathrm{s}$, the rates of axial decrease of the plasma temperature are $3 \times 10^{4} \mathrm{~K} / \mathrm{m}$ vs. $3 \times 10^{5} \mathrm{~K} / \mathrm{m}$ for laminar and turbulent plasma jets; corresponding values of axial decreasing-rates of the axial velocity and the argon mass fraction are $3 \times 10^{3}$ vs. $2 \times 10^{4}(\mathrm{~m} / \mathrm{s}) / \mathrm{m}$ and $0.4 / \mathrm{m}$ vs. $2.5 / \mathrm{m}$, 

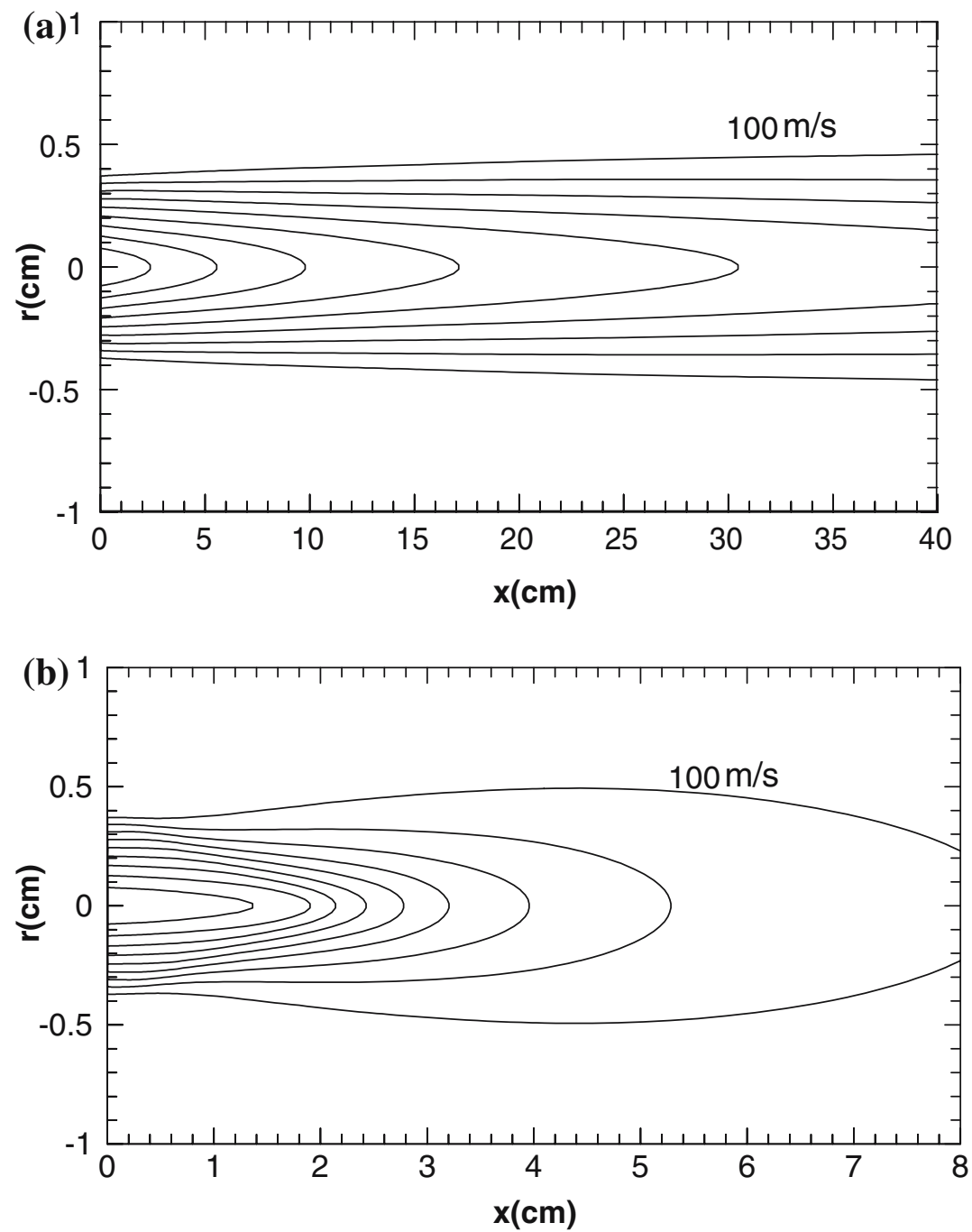

Fig. 5 Comparison of the axial-velocity contours in typical laminar (a) and turbulent (b) plasma jets $\left(U_{0}=\right.$ $\left.1000 \mathrm{~m} / \mathrm{s}, T_{0}=13,000 \mathrm{~K}\right)$. Outer line $-100 \mathrm{~m} / \mathrm{s}$; interval $-100 \mathrm{~m} / \mathrm{s}$

respectively. The jet lengths of the laminar plasma jets are thus much longer than those of the turbulent plasma jets. As the jet-inlet velocity increases, the rates of axial decrease of the plasma temperature, axial velocity and argon mass fraction decrease for the laminar plasma jets, but the axial variations of the plasma temperature and argon mass fraction are almost independent of the jet-inlet velocity for the turbulent plasma jets, as seen in Figs. 7(b) and 9(b). The present predicted results are consistent with the experimental observation shown in Fig. 1, namely the laminar plasma jet length increases appreciably with increasing jet-inlet velocity and is much longer than the turbulent plasma jet length.

Similar modeling results are presented in Figs. 10-12 concerning the axial variations of the plasma temperature, axial velocity and argon mass fraction, respectively, along the jet 

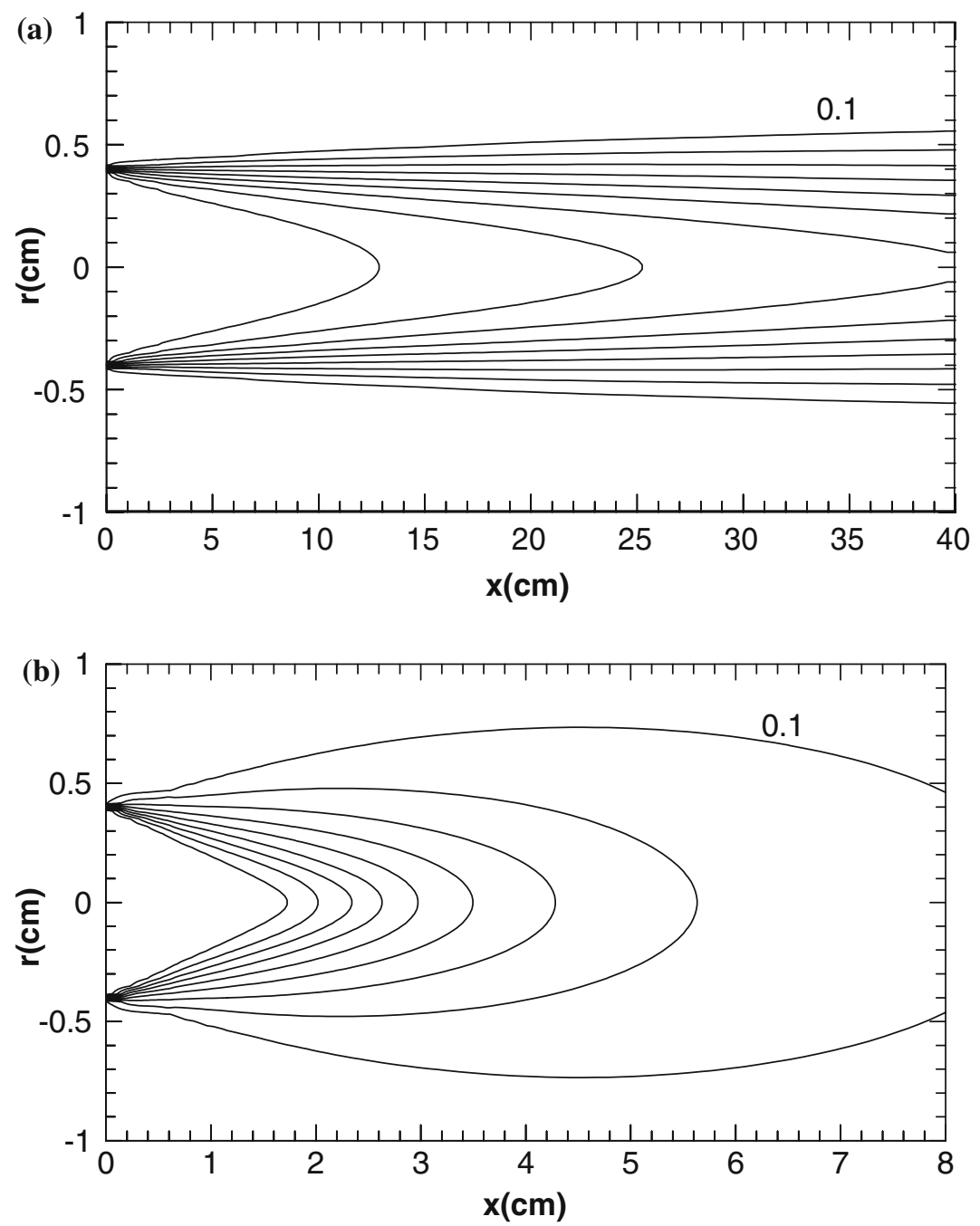

Fig. 6 Comparison of the argon mass fraction contours in typical laminar (a) and turbulent (b) plasma jets $\left(U_{0}=1000 \mathrm{~m} / \mathrm{s}, T_{0}=13,000 \mathrm{~K}\right)$. Outer line -0.1 ; interval -0.1

axis of the laminar and turbulent plasma jets but for the cases with a fixed jet-inlet velocity $\left(U_{0}=1000 \mathrm{~m} / \mathrm{s}\right)$ and different jet-inlet temperatures $\left(T_{0}=10000,13,000\right.$ and $\left.16,000 \mathrm{~K}\right)$. It is again seen that the rates of axial decrease of the plasma parameters along the jet axis for the laminar plasma jets are appreciably less than their counterparts for the turbulent plasma jets. As the jet-inlet temperature increases, the rates of axial decrease of the plasma parameters increase somewhat for the laminar plasma jets, while the axial variations of plasma axial-velocity and argon mass fraction are less influenced by the jet-inlet temperature for the turbulent plasma jets, as shown in Figs. 11(b) and 12(b).

Figure 13 shows the computed axial variations of the impact pressure, normalized to its value at the jet inlet, for the laminar and turbulent plasma jets. It is seen that generally the rates of axial decrease of the normalized impact pressure for the laminar plasma jet are much 

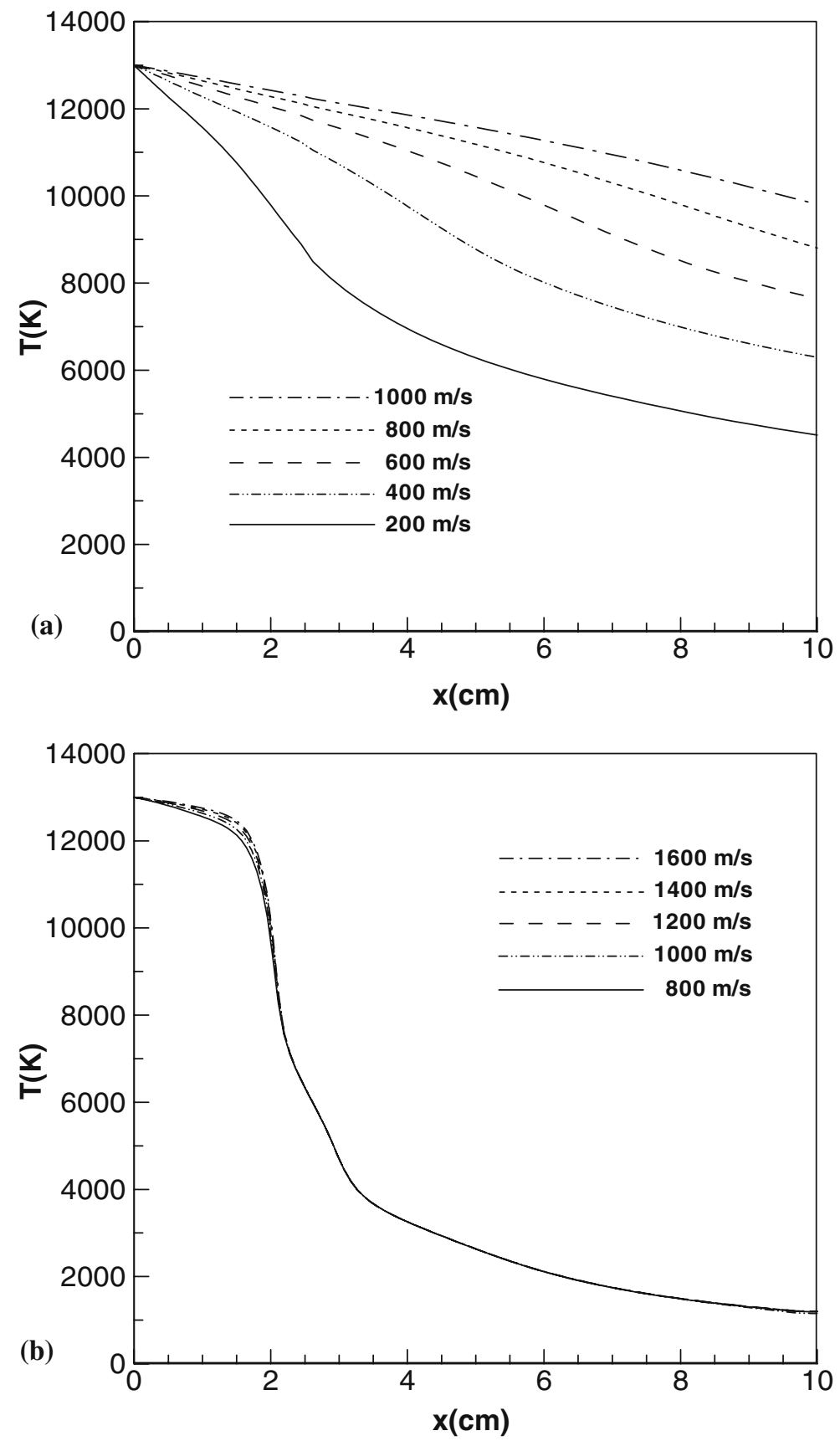

Fig. 7 Variations of the plasma temperature along the plasma jet axis for the cases with a fixed jet-inlet temperature $\left(T_{0}=13,000 \mathrm{~K}\right)$ but different jet-inlet velocities $\left(U_{0}\right)$. (a) Laminar jets; (b) turbulent jets 

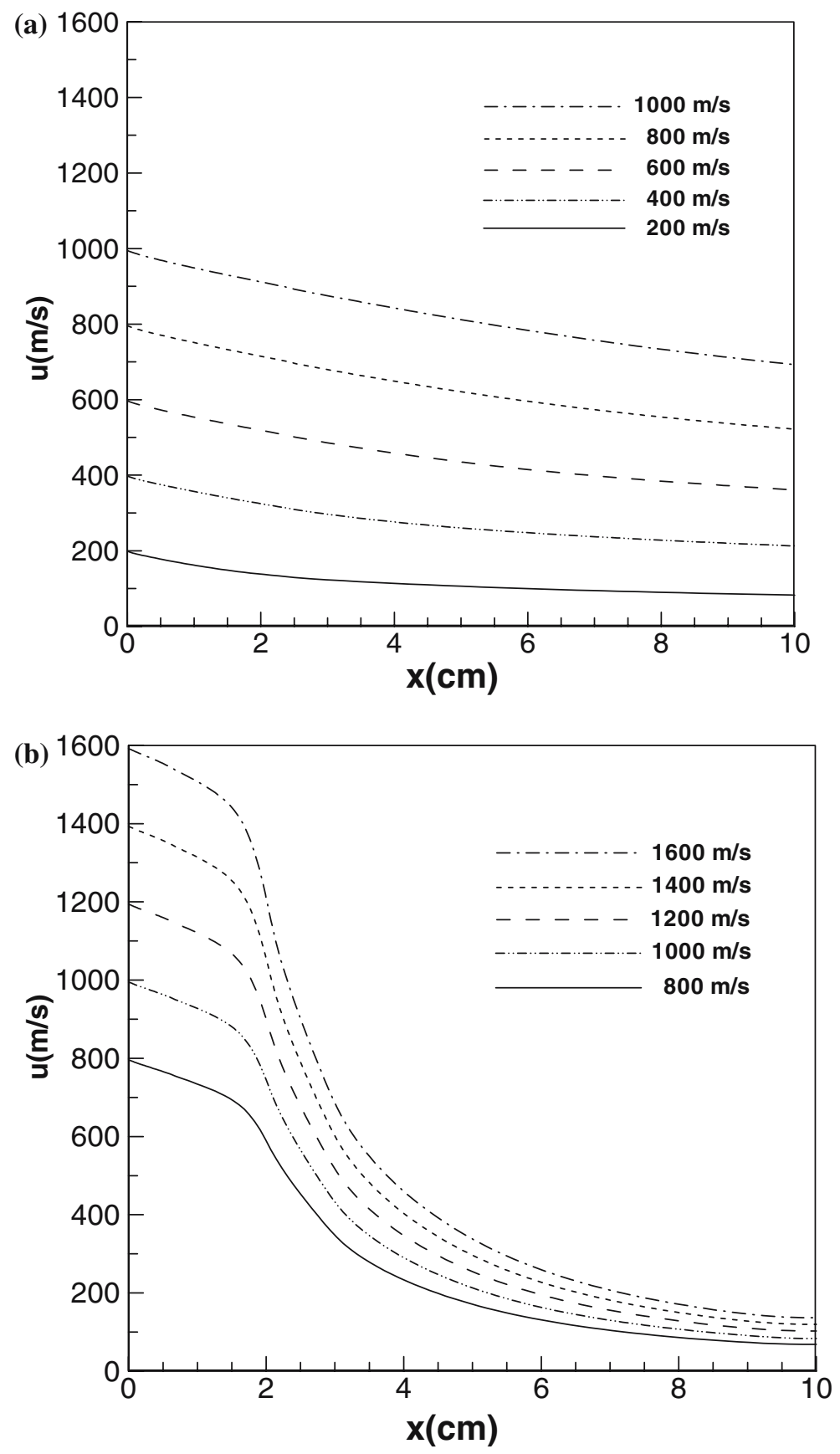

Fig. 8 Variations of the plasma axial-velocity along the plasma jet axis for the cases with a fixed jet-inlet temperature $\left(T_{0}=13,000 \mathrm{~K}\right)$ but different jet-inlet velocities $\left(U_{0}\right)$. (a) Laminar jets; $(\mathbf{b})$ turbulent jets 

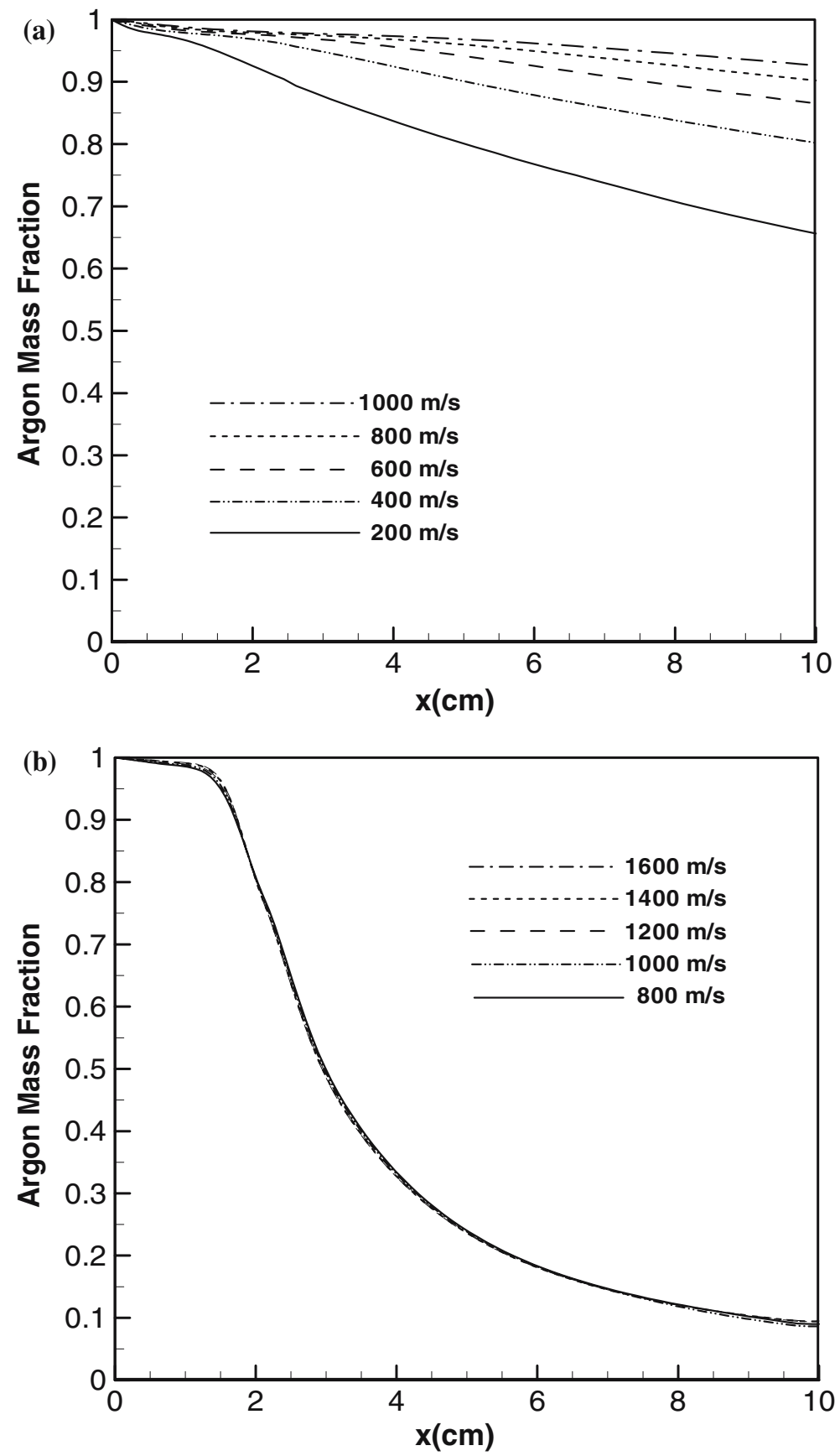

Fig. 9 Variations of the argon mass fraction along the plasma jet axis for the cases with a fixed jet-inlet temperature $\left(T_{0}=13,000 \mathrm{~K}\right)$ but different jet-inlet axial-velocities $\left(U_{0}\right)$. (a) Laminar jets; (b) turbulent jets 

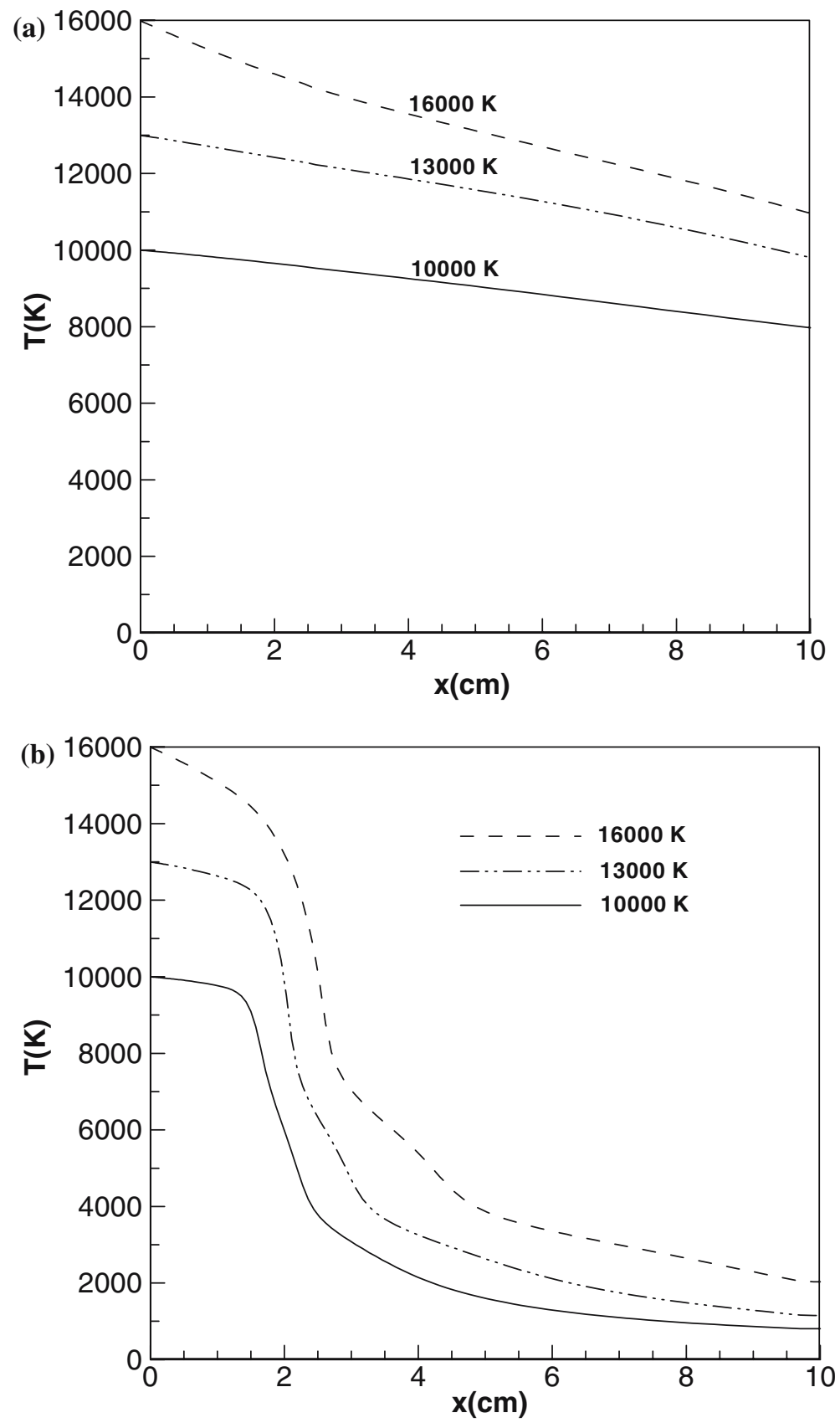

Fig. 10 Variations of the plasma temperature along the plasma jet axis for the cases with a fixed jet-inlet velocity $\left(U_{0}=1000 \mathrm{~m} / \mathrm{s}\right)$ but different jet-inlet temperatures $\left(T_{0}=10,000,13,000\right.$ and $\left.16,000 \mathrm{~K}\right)$. (a) Laminar jets; (b) turbulent jets 

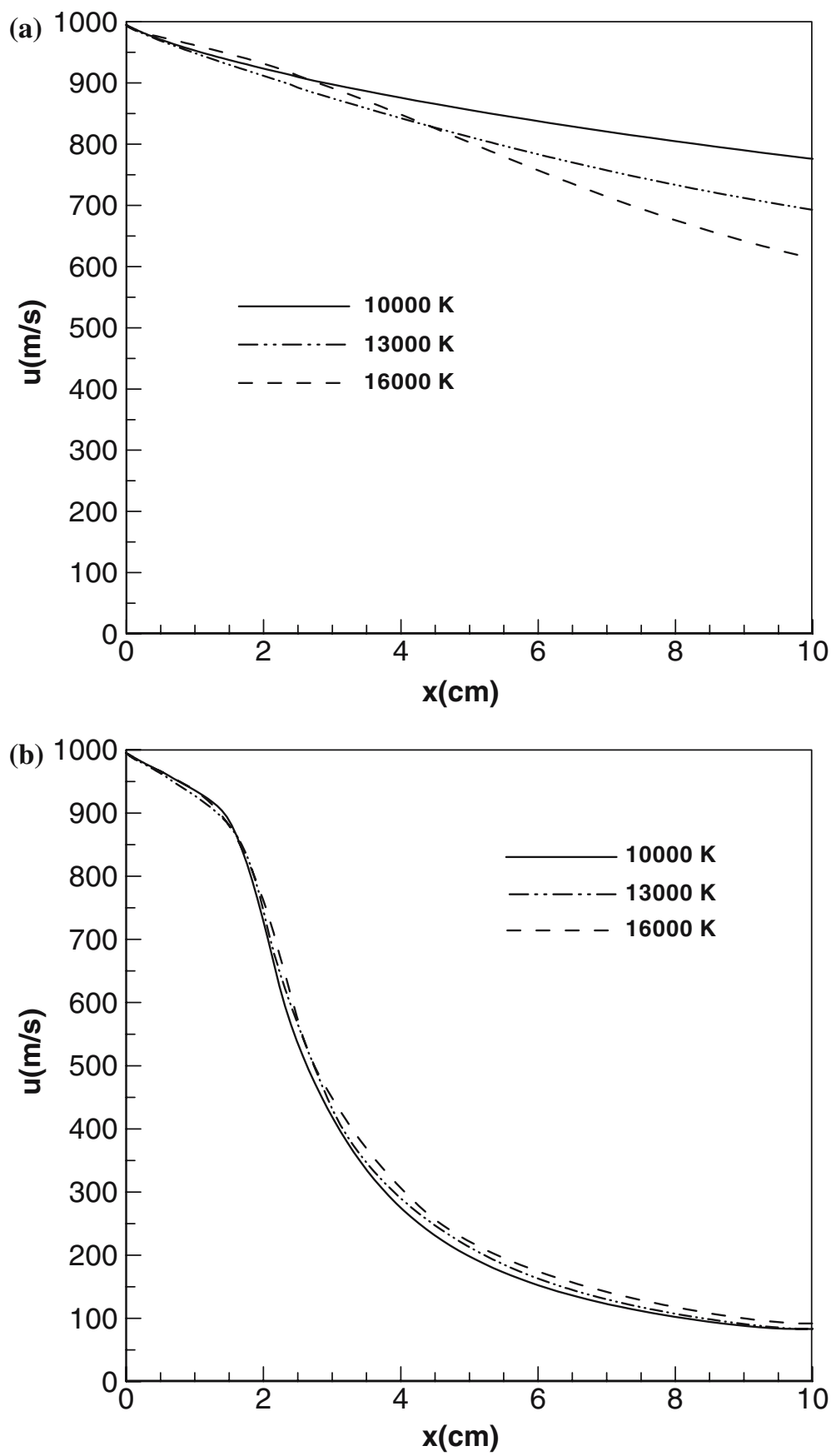

Fig. 11 Variations of the plasma axial-velocity along the plasma jet axis for the cases with a fixed jet-inlet velocity $\left(U_{0}=1000 \mathrm{~m} / \mathrm{s}\right)$ but different jet-inlet temperatures $\left(T_{0}=10,000,13,000\right.$ and $\left.16,000 \mathrm{~K}\right)$. (a) Laminar jets; (b) turbulent jets 

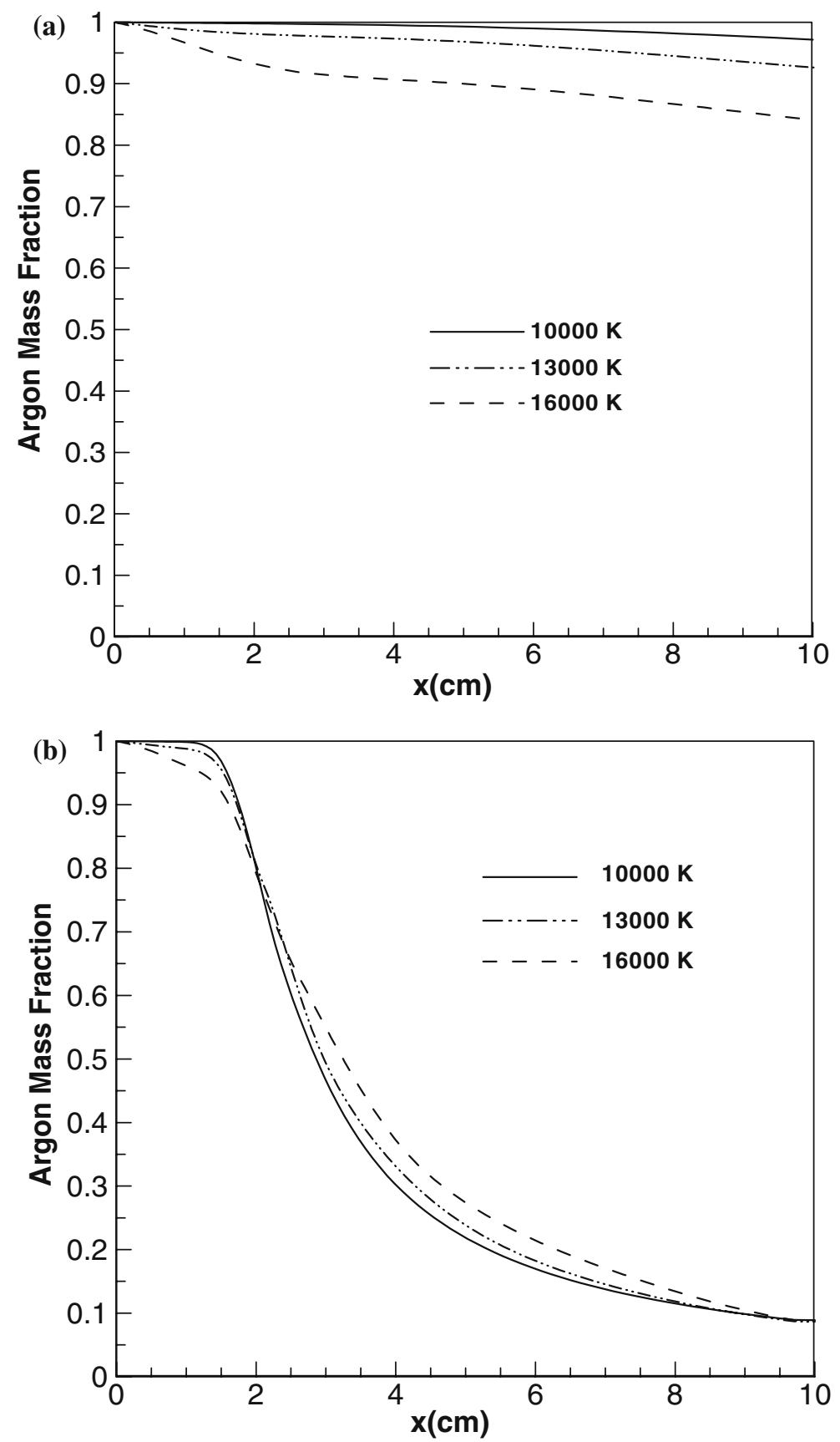

Fig. 12 Variations of the argon mass fraction along the plasma jet axis for the cases with a fixed inlet velocity $\left(U_{0}=1000 \mathrm{~m} / \mathrm{s}\right)$ but different jet-inlet temperatures $\left(T_{0}=10,000,13,000\right.$ and $\left.16,000 \mathrm{~K}\right)$. (a) Laminar jets; (b) turbulent jets 


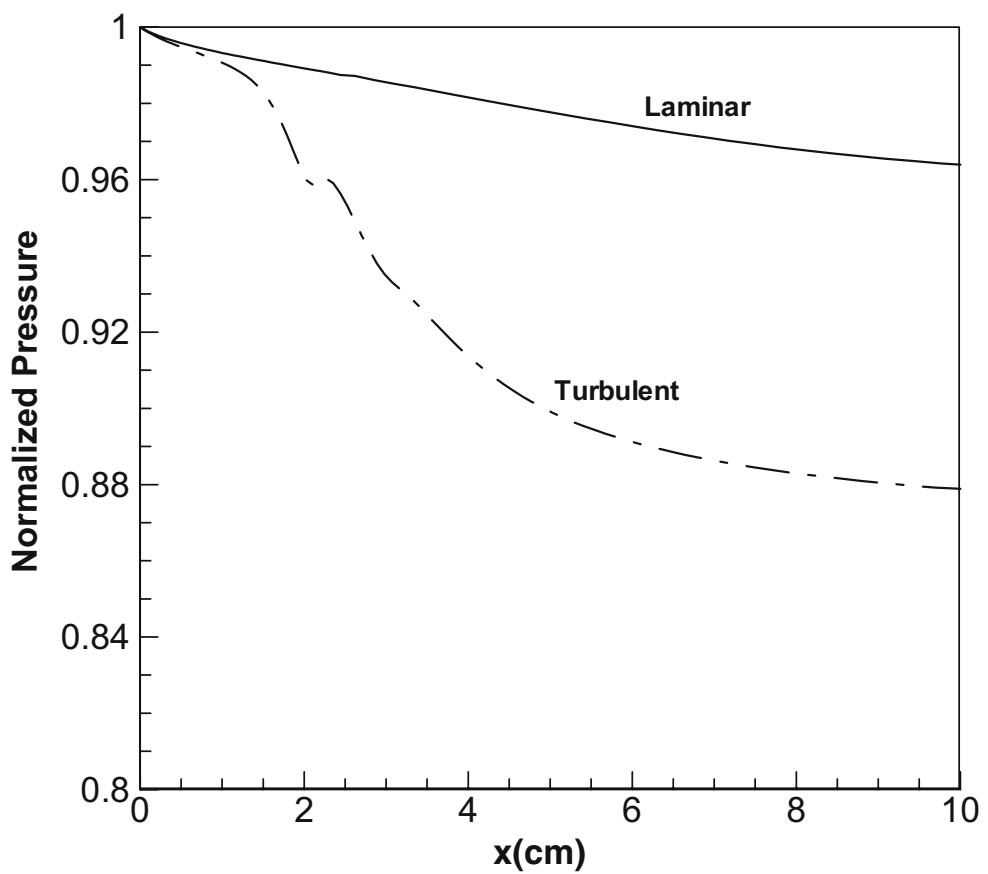

Fig. 13 Comparison of the variations of the normalized impact pressures along the axis of the laminar (full line) and turbulent (dotted line) plasma jets $\left(U_{0}=1000 \mathrm{~m} / \mathrm{s}, T_{0}=13,000 \mathrm{~K}\right)$

less than those for the turbulent plasma jet, also due to the fact that the air entrainment rate for the former is much less than that for the latter.

The large difference between the laminar and turbulent plasma jet characteristics, as shown in Figs. 3-13, can be attributed to the difference between the two types of plasma jets in their air entrainment laws. Hence, to better understand the foregoing computed results, it is helpful to study the entrainment of ambient air into the laminar and turbulent plasma jets more carefully. As is well known, for a circular laminar cold (around room-temperature) gas jet in which only molecular transport is involved, the mass flow rate of entrained surrounding gas is directly proportional to the axial distance and to the gas viscosity, i.e. $F-F_{0}=8 \pi \mu x$ [31, 32], where $\mu$ is the gas viscosity, $x$ the axial distance from the jet inlet, whereas $F$ and $F_{0}$ are local (at $x$ ) and inlet mass flow rates (hence $F-F_{0}$ is the net mass flow rate of the surrounding gas entrained into the laminar gas jet up to the axial location $x$ ). On the other hand, an experimental correlation was presented in reference 33 for the axial variation of the mass flow rate of entrained surrounding gas for turbulent cold gas jets where turbulent transport is the dominant mechanism, i.e. $F-F_{0}=0.32\left(x / d_{0}\right) F_{0}$, where $d_{0}$ is the diameter of jet inlet. It is noted that the entrainment laws are quite different for the laminar and turbulent cold gas jets. Namely, the entrained gas mass flow-rate is independent of the jet-inlet flow rate $F_{0}$ and the jet-inlet diameter but directly proportional to the gas viscosity for the laminar case, while it is directly proportional to $F_{0}$, inversely proportional to jet-inlet diameter but independent of the gas viscosity for the turbulent case. Under the thermal plasma conditions studied here, the jet average temperature and thus the gas viscosity will vary in the axial direction of the plasma jets, and thus the entrainment laws mentioned above for the cold gas jets are expected to be not completely applicable to non-isothermal plasma jets. So far no analytical expression 
or experimental correlation similar to that for the cold gas jets is available concerning the entrained gas flow rate for the laminar and turbulent plasma jets. Hence, modeling results are presented here concerning the entrainment of ambient air into the laminar and turbulent plasma jets.

Figure 14 compares the axial variations of the local mass flow rates normalized with respect to corresponding mass flow rates at the jet-inlet $\left(F / F_{0}\right)$ for laminar and turbulent plasma jets for the cases with a fixed jet-inlet temperature $\left(T_{0}=13000 \mathrm{~K}\right)$ but different jet-inlet velocities $\left(U_{0}=200,600\right.$ and $1000 \mathrm{~m} / \mathrm{s}$ for laminar plasma jets, and $U_{0}=600$, 1000 and $1400 \mathrm{~m} / \mathrm{s}$ for turbulent plasma jets). It is seen that for the laminar plasma jet, the normalized mass flow rate appreciably decreases with increasing jet-inlet velocity, but the values of $\left[\left(F / F_{0}\right)-1\right]$ or $\left[\left(F-F_{0}\right) / F_{0}\right]$ are not inversely proportional to the jet-inlet flow rate (or velocity). It means that the gas flow-rate entrained into the laminar plasma jet depends on the jet-inlet flow rate or velocity, implying a somewhat different entrainment law from the cold laminar gas jet case. On the other hand, the normalized mass flow rates are almost independent of the jet-inlet velocity (or flow rate) for the turbulent plasma jets, and this jet behavior is qualitatively consistent with the results for the cold turbulent gas jets. However, $\left[\left(F-F_{0}\right) / F_{0}\right]$ for the turbulent plasma jets are not strictly directly proportional to the axial distance $x$, and this jet behavior is somewhat different from the cold turbulent gas jets.

Figure 15 compares the axial variations of the total mass flow rates normalized with respect to corresponding jet-inlet mass flow rates of laminar and turbulent plasma jets for the cases with a fixed jet-inlet velocity $\left(U_{0}=1000 \mathrm{~m} / \mathrm{s}\right)$ but different jet-inlet temperatures $\left(T_{0}=10000,13,000\right.$ and $\left.16,000 \mathrm{~K}\right)$. It is seen that the normalized mass flow rate increases with increasing jet-inlet temperature for the laminar plasma jet, while the normalized mass flow rates depend much less strongly on the jet-inlet temperature for the turbulent plasma jets.

Figure 16 shows the computed axial variations of the absolute values of the mass flow rate of ambient air entrained into the laminar plasma jets for the cases (a) with a fixed jet-inlet temperature $\left(T_{0}=13,000 \mathrm{~K}\right)$ but different jet-inlet axial-velocities $\left(U_{0}=200,600\right.$ and $1000 \mathrm{~m} / \mathrm{s})$ and for the cases (b) with a fixed jet-inlet velocity $\left(U_{0}=1000 \mathrm{~m} / \mathrm{s}\right)$ but different jet-inlet temperatures $\left(T_{0}=10,000,13,000\right.$ and $\left.16,000 \mathrm{~K}\right)$. It is seen that for a given axial location, the entrained air mass flow-rate increases with increasing jet-inlet velocity for a fixed jet-inlet temperature and increases with increasing jet-inlet temperature for a fixed jetinlet velocity. Such an entrainment law of the laminar plasma jet is different from that for the cold laminar gas jet, and can be explained by the increase of average plasma temperature and thus of the gas viscosity along the axial direction at higher jet-inlet velocity or higher jet-inlet temperature.

In addition, modeling results presented in reference 25 showed that the gas mass flow-rate entrained into a laminar argon plasma jet depended on the type of surrounding gas. It was found that when the laminar argon plasma jet was issuing into argon instead of air surroundings, the entrained gas mass flow-rate increased due to that the value of argon viscosity was larger than that of air viscosity at the room temperature.

It is found that due to the non-isothermal features of plasma jets and due to the complexity in the variation of plasma viscosity with temperature, it is hard to express the gas entrainment law for the laminar plasma jets by using a succinct relation. However, for the turbulent argon plasma jets issuing into ambient air with $U_{0}$ in the range of $800-1600 \mathrm{~m} / \mathrm{s}$ and $T_{0}$ in the range of 10,000-16,000 K, the gas entrainment law shown in Figs. 14(b) and 15(b) can be 

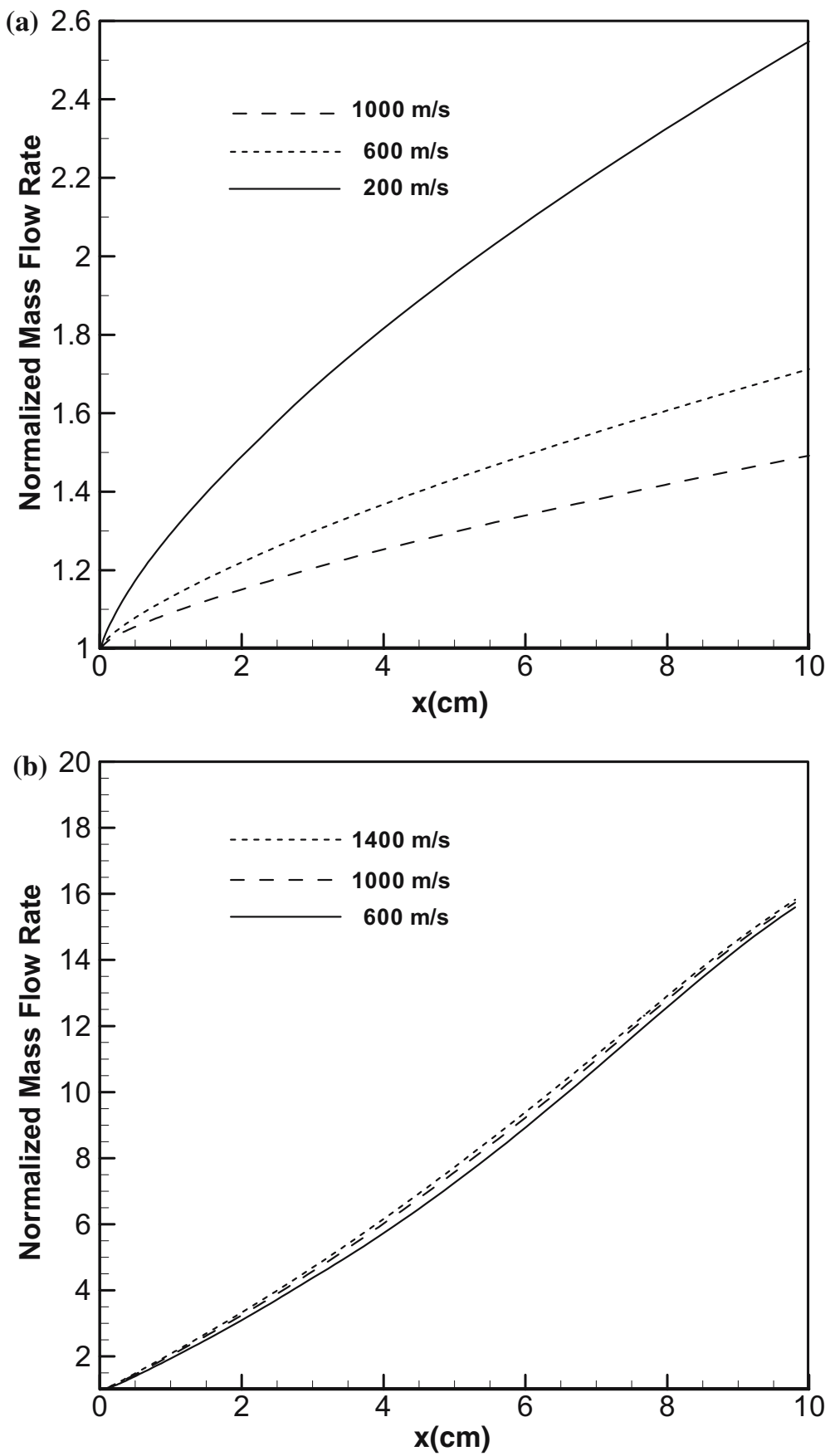

Fig. 14 Variations with the axial distance of the normalized mass flow rate of the plasma jets for the cases with a fixed jet-inlet temperature $\left(T_{0}=13,000 \mathrm{~K}\right)$ but different jet-inlet velocities $\left(U_{0}\right)$. (a) Laminar plasma jets, $U_{0}=200,600$ and $1000 \mathrm{~m} / \mathrm{s}$; (b) turbulent plasma jets, $U_{0}=600,1000$ and $1400 \mathrm{~m} / \mathrm{s}$ 

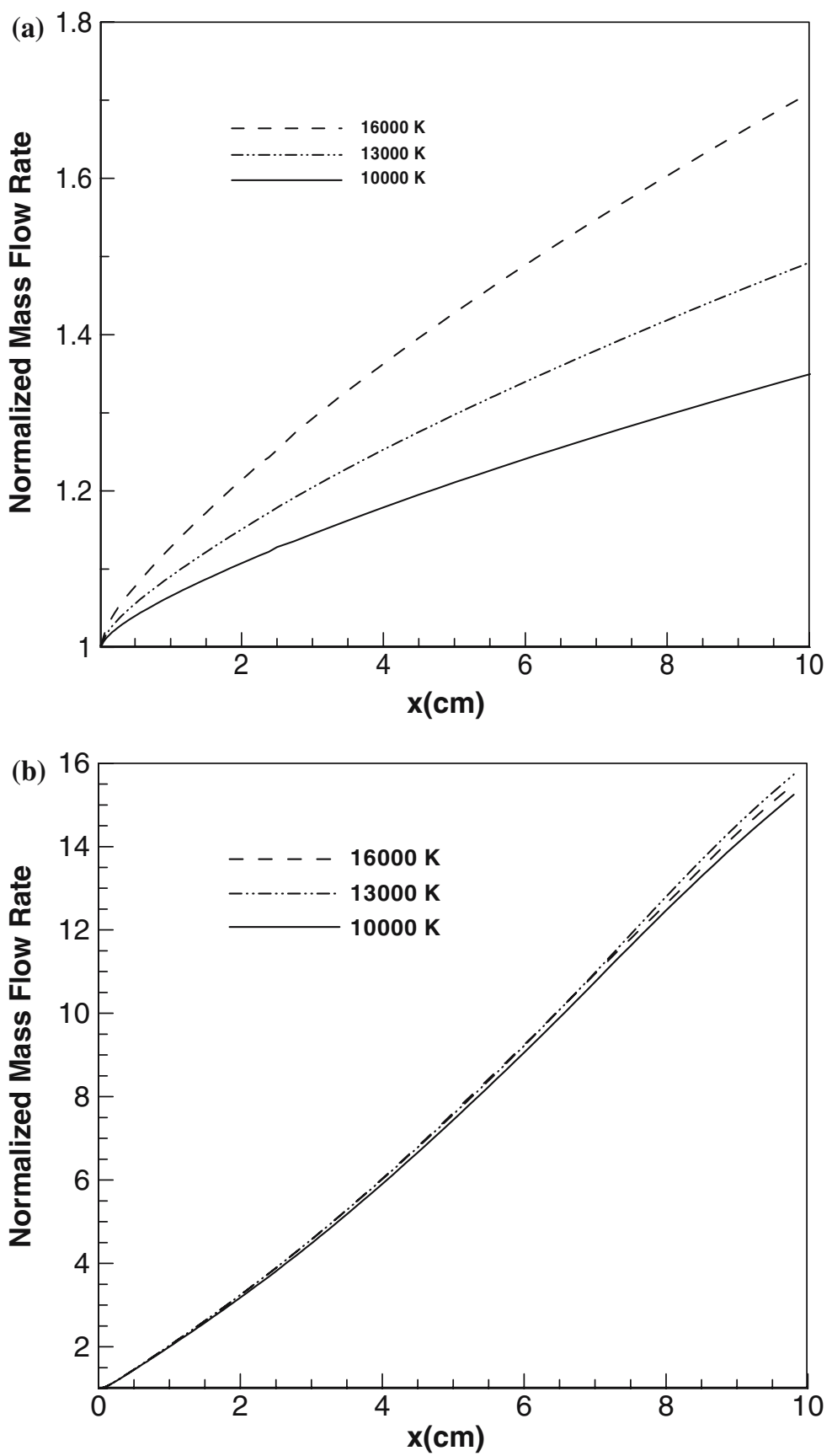

Fig. 15 Variations with the axial distance of the normalized mass flow rates for the cases with a fixed jet-inlet velocity $\left(U_{0}=1000 \mathrm{~m} / \mathrm{s}\right)$ but three different jet-inlet temperatures $\left(T_{0}=10,000,13,000\right.$ and $\left.16,000 \mathrm{~K}\right)$. (a) Laminar jets; (b) turbulent jets 

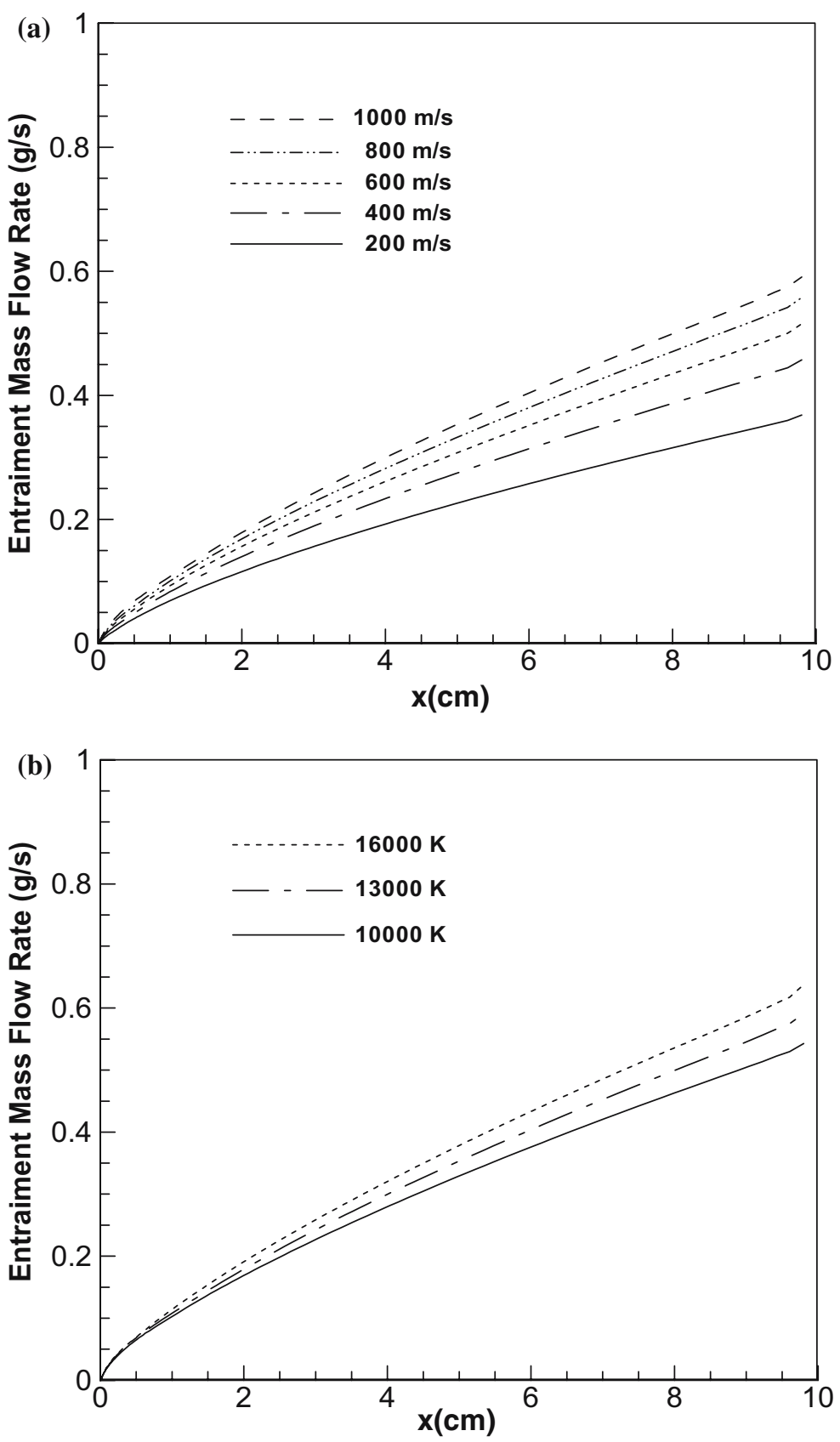

Fig. 16 Variations with the axial distance of the absolute values of the mass flow rate entrained into the laminar plasma jets. (a) for the cases with a fixed jet-inlet temperature $\left(T_{0}=13,000 \mathrm{~K}\right)$ but different jet-inlet velocities $\left(U_{0}=200,400,600,800\right.$ and $\left.1000 \mathrm{~m} / \mathrm{s}\right)$; (b) for the cases with a fixed jet-inlet velocity $U_{0}=1000 \mathrm{~m} / \mathrm{s}$ but different jet-inlet temperatures $\left(T_{0}=10,000,13,000\right.$ and $\left.16,000 \mathrm{~K}\right)$ 
expressed using the following empirical correlation:

$$
\frac{F}{F_{0}}=1+0.8\left(\frac{x}{d_{0}}\right)+0.03\left(\frac{x}{d_{0}}\right)^{2}
$$

So far we cannot predict the critical conditions for the transition from the laminar flow regime to the unsteady transitional flow state and from the unsteady transitional flow state to the turbulent flow regime, although the critical conditions for the transitions have been determined experimentally in reference 21 .

\section{Conclusions}

Modeling results are presented to compare the characteristics of laminar and turbulent argon plasma jets issuing into ambient air. It is shown that since significant differences exist between laminar and turbulent plasma jets in their ambient air entrainment mechanisms and thus in their entrained-air mass flow-rates, laminar and turbulent plasma jet characteristics are quite different. The high-temperature region length is much longer and the spreading angle is much less for the laminar plasma jet than the turbulent plasma jet. The laminar plasma jet length appreciably increases with increasing jet-inlet velocity or increasing jet-inlet temperature, while the turbulent plasma jet length is less influenced by the jet-inlet velocity or jet-inlet temperature. These predictions agree reasonably with the experimental observations.

Acknowledgments This work was supported by the National Natural Science Foundation of China (Nos. $50336010,50276065,10405015)$. The authors would like to thank Dr. A. B. Murphy, whose property tables for the argon-air plasmas were used in this study.

\section{References}

1. Pfender E (1999) Plasma Chem Plasma Process 19:1

2. Fauchais P (2004) J Phys D: Appl Phys 37:R86

3. McKelliget J, Szekely J, Vardelle M, Fauchais P (1982) Plasma Chem Plasma Process 2:317

4. Chyou YP, Pfender E (1989) Plasma Chem Plasma Process 9:291

5. Pfender E, Fincke J, Spores E (1991) Plasma Chem Plasma Process 11:529

6. Murphy AB, Kovitya P (1993) J. Appl Phys 73:4759

7. Fincke JR, Chang CH, Swank WD, Haggard DC (1994) Int J Heat Mass Transfer 37:1673

8. Bauchire JM, Gonzalez JJ, Gleizes A (1997) Plasma Chem Plasma Process 17:409

9. Vardelle A, Fauchais P, Dussoubs B, Themelis NJ (1998) Plasma Chem Plasma Process 18:551

10. Li H-P, Chen Xi (2002) Plasma Chem Plasma Process 22:27

11. Ramachandran K, Nishiyama H (2002) J Phys D: Appl. Phys. 35:307

12. Fincke JR, Crawford DM, Snyder SC, Swank WD, Haggard DC, Williamson RL (2003) Int J Heat Mass Transfer 46:4201

13. Williamson RL, Fincke JR, Crawford DM, Snyder SC, Swank WD, Haggard DC (2003) Int. J. Heat Mass Transfer 46:4215

14. Cheng K, Chen Xi (2004) Int J. Heat. Mass. Transfer. 47:5139

15. Kuz'min VI, Solonenko OP, Zhukov MF (1995) In Proc. 8th National Thermal Apray Conf., Sept. 11-15, 1995, Houston, pp. 83-88

16. Osaki K, Fukumasa O, Kobayashi A (2000) Vacuum 59:47

17. Pan WX, Zhang WH, Zhang WH, Wu CK (2001) Plasma Chem Plasma Process 21:23

18. Pan WX, Ma W, Wu CK (2002) Plasma Chem Plasma Process 22:271

19. Pan WX, Ma W, Wu CK (2001) In Zhou YC et al (eds) Mechanics and material engineering for science and experiments. Science Press, Beijing, pp. 427-431

20. Pan WX, Meng X, Li G, Fei QX, Wu CK (2005) Surf Coat Technol 197:345

21. Pan WX, Meng X, Chen Xi, Wu CK (2006) Plasma Chem Plasma Process 26:(submitted) 
22. Xu D-Y, Chen Xi, Cheng K (2003) J Phys D: Appl Phys 36:1583

23. Cheng K, Chen Xi (2004) J Phys D: Appl Phys 37:2385

24. Xu D-Y, Chen Xi, Pan WX (2005) Int J Heat Mass Transfer 48:3253

25. Xu D-Y, Chen Xi (2005) Int Commun Heat Mass Transfer. 32:939

26. Pan WX, Li G, Meng X, Ma W, Wu CK (2005) Pure Appl Chem 77:373

27. Murphy AB (1993) Phys Rev E 48:3594

28. Murphy AB (1995) Plasma Chem Plasma Process 15:279

29. Murphy AB (1996) J Phys D: Appl Phys 29:1922

30. Patankar SV (1980) Numerical heat transfer and fluid flow. Hemisphere, Washington, pp. 115-146

31. Schlichting H (1979) Boundary layer theory, 7th edn. McGraw-Hill, New York, pp. 230-234

32. Loitsyanski LG (1963) Laminar boundary layer. Physico-Mathematic Literature, Moscow, pp. 167-172 (in Russian)

33. Ricou F, Spalding DB (1961) J Fluid Mech 11:21 